\title{
Design of Common Data Distributed Loading in Marketing Real Time Cost Control System
}

\author{
Libo Xu*, Jue Bo, Yonghui Han, Yuanqi Yu, Liyang Liu \\ State Grid Liaoning Electric Power Co.Ltd, Shenyang, Liaoning 110005, China \\ *Email: nike67242@163.com
}

\begin{abstract}
Remote real-time control of cost is an important measure to improve the level of enterprise marketing management. The common data distributed design of marketing real-time cost control system is more intelligent and convenient. The distributed loading design of common data in marketing real-time cost control system can not only improve the transaction level of power companies, but also greatly improve the marketing efficiency of power companies and better serve users. In order to improve the operation effect of marketing real-time cost control system, the distributed loading of common data in marketing real-time cost control system is designed. This paper studies the application prospect of distributed loading of common data in marketing real-time cost control system, analyzes its function and influence, and puts forward optimization scheme, which provides reference for power enterprises to carry out cost control business and marketing.
\end{abstract}

Keywords: marketing, real time cost control, data distribution, data loading

\section{INTRODUCTION}

The existing marketing real-time cost control system makes full use of the existing system software, hardware and network resources, inherits valuable data resources according to relevant standards and data specifications. According to the development trend of the future region, grasp the changes of internal and external environment, make the planning adapt to the future development, and flexibly meet the application requirements ${ }^{[1]}$. In order to meet the needs of real-time cost control business of electric power companies, a special investigation on Optimization and upgrading of distributed cost control is carried out, and a design method of distributed data loading commonly used in marketing real-time cost control system is proposed. Based on decentralized marketing, the real-time marketing cost control system is optimized and upgraded in real time, providing better service for cost control users in the whole province, providing concise, flexible and friendly operation interface, improving the working efficiency of the realtime marketing cost control system, and facilitating the comprehensive management and analysis of cost control users $^{[2]}$. Through the analysis of the data, process and server performance index of the existing marketing cost control business, this paper analyzes the problems and causes of the current cost control business, probes into the feasibility of adopting the cost control strategy in the distributed environment, formulates the real-time marketing scheme and technical scheme of the distributed cost control system, and analyzes the business structure, application structure and data According to the needs of cost control, the cost control requirements of enterprises are verified by experiments, and suggestions on cost control work are put forward, and the cost control system is optimized and improved $^{[3]}$. Optimize and upgrade the cost control business, improve the customer service level of cost control, and provide convenient and fast service for users.

\section{COMMON DATA SAMPLE COLLECTION OF MARKETING REAL TIME COST CONTROL SYSTEM}

In order to collect the remote real-time cost control system of electric power marketing, so as to optimize the design of data distribution, firstly, through data collection, the big data sample analysis model of marketing real-time cost control system is established. The collected multi-dimensional power marketing remote real-time cost control database includes ${ }^{[4]}$. The number of storage resources of each power marketing remote real-time cost control information is $\mathrm{x} 1, \mathrm{x} 2, \ldots, \mathrm{xn}$. The structure mapping parameters of the remote cost 
control information of electric power marketing in mdimension characteristic domain are collected. The random distribution characteristic sample set $\mathrm{K}$, $\mathrm{K}=1,2, \ldots, \mathrm{n}$, , fuzzy weighting coefficient is $\mathrm{d}$. The characteristic function of the remote real-time cost control data of power marketing is reconstructed as a by piecewise fitting the control value as $\mathrm{p}$, and the output $\mathrm{Xi}(\mathrm{T})$ of the sample sequence is obtained ${ }^{[5]}$. In the storage space of the remote real-time cost control data of the power marketing, the fuzzy comprehensive sequence method is used to obtain the feature extraction formula of the data

$$
\tau^{*}(p)=\frac{\theta\left(p^{*} d, q^{*} d\right)}{\mathrm{X}_{\mathrm{i}}(\mathrm{T})+\alpha\left(p^{*} l, q^{*} l\right)}
$$

Aiming at the adaptive receiving control value s of the data management node in the remote real-time cost control management node of the power market, the measurement data reconstruction method is used to establish the feature detection and statistics ${ }^{[6]}$. According to the data characteristic distribution of the measurement data, the node is optimized, and the statistical analysis model of the real-time cost control is established, and the real-time is obtained through the structure model of the acquisition system Cost control information. Aiming at the real-time of power marketing, a real-time data acquisition method is proposed.

$$
\Delta X=\left[s_{1}, s_{2}, \cdots s_{K}\right]=\left[\begin{array}{cccc}
x_{1} & x_{2} & \cdots & x_{K} \\
x_{1+\tau} & x_{2+\tau} & \cdots & x_{K+\tau} \\
\cdots & \cdots & \cdots & \cdots \\
x_{1+(m-1)} \tau & x_{2+(m-1)}+ & \cdots & x_{M+\mid m-1)} r
\end{array}\right]
$$

Among them:

$$
K=N-(m-1) \tau^{*}(p)
$$

By describing the embedded dimension $\mathrm{m}$ of control information distribution of remote power marketing cost $\mathrm{N}$, combined with the measurement of network structure parameters, the load balancing algorithm of remote power marketing cost control information is obtained as follows:

$$
L_{1}=\Delta X \sum_{i=1}^{n}\left(K s_{i}+\sum_{p=1}^{s_{i}} l_{p}\right)
$$

After testing the distribution parameters of the system, the characteristics of the real-time cost control information in the remote power market are extracted, and the detection statistical characteristics of the realtime cost control information are obtained:

$$
p\left(R^{\mathrm{N}}=r_{i}\right)=p\left(\begin{array}{l}
X^{\mathrm{N}}=x_{i} \| x_{i}|=| r_{i} \mid, \text { angle }\left(x_{i}\right) \\
=\left(\operatorname{angle}\left(r_{i}\right)-\varphi_{g}\right) \bmod (2 \pi)
\end{array}\right)
$$

In this paper, a deviation detection method based on rough set decomposition for DC distribution system is proposed.

$$
H\left(R^{\mathrm{N}}\right)=-\sum_{i=1}^{M} p\left(r_{i}\right) \log \left(p\left(r_{i}\right)\right)=-\sum_{i=1}^{M} p\left(x_{i}\right) \log \left(p\left(x_{i}\right)\right)=H\left(X^{\mathrm{N}}\right)
$$

In order to realize the integration dimension of remote real-time cost control big data in power marketing system, the line spectrum characteristic quantity of remote real-time cost control information is extracted.

$$
d(p, o)=\sqrt{\left(x_{i}-x_{j}\right)^{2}+\left(y_{i}-y_{j}\right)^{2}}
$$

Among them, $\mathrm{p}\left(\mathrm{x}_{\mathrm{i}}, \mathrm{y}_{\mathrm{i}}\right), \mathrm{o}\left(\mathrm{x}_{\mathrm{j}}, \mathrm{y}_{\mathrm{j}}\right) \in \mathrm{D}_{\mathrm{S}}$, remote real-time segmented fusion of power marketing cost information, information fusion output k-order statistics $c_{h x}=\left(\tau_{1}, \cdots, \tau_{k-1}\right)$. By combining the distortion fusion results with the total loss of DC voltage harmonics, the remote real-time cost control information collection and grouping matching in power market are realized, and the adaptive matching ability of cost control is improved.

\section{REALIZATION OF COMMON DATA DISTRIBUTED LOADING IN MARKETING REAL TIME COST CONTROL SYSTEM}

The remote real-time cost control of power grid is to realize the automatic estimation of the residual power and cost of local power system by comparing the relevant information of users with the prepayment information, and by collecting the power consumption information of the user and pushing the real-time (quasi real-time) indication information into the electric energy meter, and setting the data alarm capacity and overdraft threshold of the marketing real-time cost control system In order to complete the common data distribution loading and recovery instructions of marketing real-time cost control system ${ }^{[7-9]}$. At the business level, data distribution loading refines, abstracts and summarizes the core business of marketing remote real-time cost control application, forms a comprehensive data distribution loading structure view commonly used in 
marketing real-time cost control system, and provides important management basis for data distribution loading and data structure. Data distribution loading defines the application function of marketing real-time cost control system, and according to the system The application function forms the application view of marketing remote real-time cost control ${ }^{[10-12]}$. The marketing real-time cost control system is distributed and loaded to define various system components, integration relationships, deployment methods and system security assurance. Marketing distributed cost control system refers to the system that optimizes and upgrades the software distribution structure of marketing real-time cost control system in order to improve the performance of marketing type decentralized cost control system. In addition, the marketing cost control system has strong scalability. The application architecture design of the distributed cost control system fully conforms to the application architecture design principles and standards of State Grid Corporation of China. On the basis of big data collection of provincial companies, a set of cost control management system covering cost control strategy management, user group management, cost control execution exception management, electric energy metering service, advanced cost control application and cost control information generation service is established, which is applied in provincial company headquarters, local companies and grass-roots units to realize marketing business application. The information exchange of user power consumption information acquisition system promotes the development of cost control business. Based on the above structure, using distributed cost control system, the calculation time can reach 45 minutes, the average CPU utilization rate is $50 \%$, the average memory is $48 \%$, and the average I / O is $40 \%$. The degree of hardware automation is greatly improved, and the computing speed can reach 20 million users per hour. For the cost control system, 24 million users need to be divided into five concentrators, one for five days and one for one day, with an average of 5 million units per day and 1.2 million units per hour. After 4-5 hours of calculation. Using the distributed cost control system, 24 million users only need to calculate the cost once a day, and the time is 1-1.5 hours, 20 million per hour. In order to make the remote real-time cost control data set of power market obtain limited data distribution, the distribution function $\mathrm{f}(\mathrm{Y} 1, \mathrm{Y} 2, \ldots)$ is used ) To represent the joint distribution function in the feature space. Then the calculation results are as follows:

$$
p_{i}=f\left(d_{i} d_{i}^{\prime}\right) / N=T_{i}, O_{j \cdot f_{1}}, \cdots, O_{j, f_{2}}, T_{i}, \cdots, T_{i}, O_{n, f_{i}}, \cdots, O_{n, f_{i}}
$$

In the model, $\mathrm{Ti}$ is the eigenvalue of remote realtime cost control information of power marketing system. By using the key feature detection and query method based on big data, the fitness function of cost control information $\langle\mathrm{OJ}, 1, \mathrm{OJ}, \mathrm{f}\rangle, \mathrm{Ti} *\{\mathrm{~T} 1, \mathrm{~T} 2, \mathrm{~T} 31$, $\mathrm{T} 32$ \}, OJ, F1, F, OJ, FN is the fitness function of cost control big data of remote power marketing. The EST independent regional template function NIJ $<\mathrm{m}$ is obtained. By using fuzzy region and fuzzy technology, the information fusion characteristic quantity $\mathrm{Xi}, \mathrm{Yi}$ of power marketing remote real-time cost control is obtained. The optimal $\mathrm{H} 2$ characteristic solution is:

$$
L_{1}=\sum_{i=1}^{n}\left(s_{i}+\sum_{p=1}^{s_{i}} l_{p}\right)
$$

In the above formula, L1, L2 and LSI represent the adaptive grouping matching fusion feature under $\mathrm{RX}(\tau)$ boundary conditions, which are suitable for real-time cost control big data processing in remote power market. On this basis, by constructing the information fusion model constrained by association rules, the real-time big data samples in the process of remote power marketing are located, and the real-time big data query is carried out to obtain the optimal control law

$$
T=\left\{\left(x_{1}, y_{1}\right),\left(x_{2}, y_{2}\right), \cdots,\left(x_{i}, y_{i}\right), \cdots,\left(x_{i}, y_{l}\right)\right\}
$$

On this basis, comprehensive scheduling method query and adaptive scheduling are adopted to realize the analysis of big data of remote real-time cost control of power marketing, and improve the management ability of remote real-time cost control. The fuzzy partition method is applied to the automatic clustering analysis of cost control information of remote power marketing, and the fuzzy fitting degree is obtained

$$
O\left(L O F_{k}(p)\right)=O\left(\operatorname{lr} d_{k}(p)\right)+O\left(N_{k \text {-lin }|p|}\right)+O\left(\operatorname{lr} d_{k}\left(o_{i} \in N_{k \text {-diat } p p}\right)\right)=O\left(m^{*} n\right)
$$

Combined with the statistical analysis method of voltage deviation and voltage sag, an adaptive scheduling method suitable for spatial distribution of real-time cost control information in remote power market is proposed. Aiming at the problem of information fusion in remote real-time detection of power market, a feature point detection model based on big data is proposed.

$$
\begin{gathered}
\hat{\mu}_{k+1}=\hat{\alpha} \bar{\mu}+(1-\hat{\alpha}) \hat{\mu}_{k} \\
\hat{\sigma}_{k+1}=\hat{\beta}_{k} \tilde{\sigma}+\left(1-\hat{\beta}_{k}\right) \hat{\mu}_{k}
\end{gathered}
$$

On the basis of this model, the fuzzy information feature detection method is applied to the power marketing remote real-time big data feature detection and extraction, which improves the ability of big data fusion and real-time control. The original cost control system uses the traditional data warehouse storage mode, which can not effectively store the growing business data. With the development of Commerce, the amount of data is increasing, the application is more and 
more complex, and the requirement of data processing is also higher and higher. However, data warehouse can not be linear expansion, difficult to manage, high cost, expansion pressure, low efficiency. Based on this, we further optimize the distributed loading method, use HbAS database for distributed cost control, and establish a high reliability, high performance, column oriented and highly scalable HDFS distributed column storage system to expand additional cheap commercial servers without downtime maintenance. Through the cost sharing control mode, users can enjoy more perfect and in place services, comprehensively improve the power supply service level of power supply enterprises, achieve fair treatment for different customers, effectively improve the efficiency of common data distribution loading of marketing real-time cost control system, and provide more convenient and superior power consumption conditions for users. After the electricity user pays the electricity fee every month, the traditional payment method will lead to the default of the power user, and even cause the contradiction between the power supplier and the user. In the common data distribution loading mode of marketing real-time cost control system, the system can effectively send arrears reminder to users, and realize the monitoring of arrears shutdown mode to users, so as to prevent arrears shutdown problems. Strengthen the practical application of remote power consumption control system, better adapt to the construction and development of modern smart grid, reduce the difficulty of smart meter measurement and monitoring, and promote the further development of power grid enterprises.

\section{ANALYSIS OF EXPERIMENTAL RESULTS}

In the experimental work, the server side of the system adopts the network server deployment architecture, and uses the server hardware of the company's information room to build a set of hardware support system for network service publishing and data storage. In terms of function realization, the marketing real-time cost control analysis system adopts the distributed research and development technology based on Java Web, and provides the following configuration for the development platform by using MyEclipse-E environment: Java EE 7, J2EE platform version. The development tool uses MyEclipse version 15.0. The programming language is java language and JSP script language. The web design tool is Dreamweaver v8.0. SM framework tool, spring4.2, springmvc4.2, mybatis3.2, web service publishing tool. The database is oracle $11 \mathrm{G}$. The table lists the hardware configuration of application server host and database server host selected by system server. Based on this, the experimental environment parameters are standardized as follows:
Table 1 Experimental parameter setting

\begin{tabular}{ll}
\hline equipment & performance parameter \\
\hline Processor & Intel i7 dual core 3 3GHz server \\
selection & version \\
Memory chip & DDR3 dual channel 16GB chip \\
operating system & Windows Server 2008 version
\end{tabular}

The selected customer test host uses the PC deployed in the company. Using web browser software to realize the host access to system functions. The cost calculation results of distributed cost control system and market system are compared to verify the correctness of the cost calculation method, and the results are applied to the cost calculation strategy. Contrast content:

1) The measurement process is divided into two stages: the first stage measures the electricity charges of the original load control system in the charge control system and corresponds to the market system; the second stage measures the electricity charges of residents and low-voltage users in the cost control system and corresponds to the market system

2) The quantitative comparison test is synchronized with the functional test of the test system.

3) The comparison method is applicable to all users of provincial companies and compared with the cost of the last two months.

4) The trial calculation parameters of environmental cost control system and the allocation of pre estimation cost parameters by market system method.

5) Data transmission: input market data list synchronously according to the cost control system, and conduct revolution comparison and integrity check on the user data and monthly meter reading data of the measured unit in the cost control system database.

6) the FCO task engine calls FCO before calculating the cost to prepare data to verify the preparation results.

7) With the billing function of the billing control system, the electricity and electricity charges can be charged in batches.

8) This paper calculates the cost control system, compares the cost control effect of the two systems, analyzes the reasons for the inconsistent results, and forms the difference table and the reason table.

Table 2 experimental methods and steps

\begin{tabular}{cl}
\hline classification & Selection scheme \\
\hline \multirow{3}{*}{ Technology selection } & Interface display technology: \\
& Server development \\
\hline
\end{tabular}




\begin{tabular}{cl}
\hline & technology: JDK1.5 above, \\
& javaee5.0 above, CC++ \\
& Data access technology: JDBC \\
Deployment mode & Provincial company deployment \\
& It adopts the same development \\
& platform as the marketing \\
Development & business system application \\
platform & system \\
& application server: Web logicllg \\
middleware & Message queuing server: Kafka \\
& Distributed cache server: Redis \\
Data replication & Oracle Golden Gatellg \\
software & \\
database & Oraclellg、 H Base \\
operating system & Linux \\
\hline
\end{tabular}

FPGA and DSP logic control processing program are used to realize the application effect of power marketing cost remote real-time control and big data analysis system. According to the experimental results, FPGA and FPGA are designed DSP logic processing program, and its hardware debugging, real-time acquisition of 3000 power marketing big data are analyzed, through the collection and analysis of system data distribution, compared with the traditional method and the method of this paper in the process of data loading convergence analysis, in which, the higher the convergence, the better the data processing effect, Record and analyze the experimental results, as shown in the figure 1 .

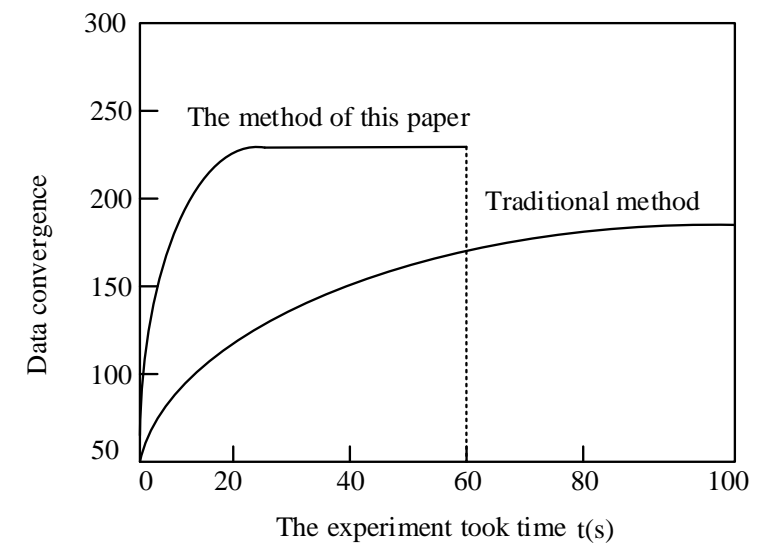

Fig. 1 Comparison of real-time performance and convergence

It can be seen from the analysis chart that the commonly used data distribution loading method of marketing real-time cost control proposed in this paper has better convergence and relatively lower timeconsuming in the actual application process, which proves that the data distribution loading method has good real-time performance, stable and reliable work, and better guarantee the operation effect of marketing real-time cost control system.

\section{CONCLUSION}

According to the marketing cost control business process, data and cost control server performance indicators of monitoring business process under the current market environment, this paper studies the distributed deployment scheme of cost control strategy application execution function module, the optimization scheme of work order strategy of distributed cost control system and related statistical analysis content, and puts forward the common data of marketing realtime cost control system In order to improve the efficiency of marketing cost control and improve the level of customer service.

\section{ACKNOWLEDGMENT}

This work was supported by State Grid Liaoning Electric Power Co., Ltd. science and technology project funding (Project No.: 2020YF-73).

\section{REFERENCES}

[1] Canete-Carmona E , Gallego-Martinez J J , Martin C , et al. A Low-Cost IoT Device to Monitor in RealTime Wine Alcoholic Fermentation Evolution through CO2 emissions[J]. IEEE Sensors Journal, 2020, PP(99):1-1.

[2] García Guzmán Javier, Prieto González Lisardo, Jonatan P R , et al. Real-Time Vehicle Roll Angle Estimation Based on Neural Networks in IoT LowCost Devices[J]. Sensors, 2018, 18(7):2188-2189.

[3] Yin L , Yu T , Zhang X , et al. Relaxed deep learning for real-time economic generation dispatch and control with unified time scale[J]. Energy, 2018, 149(APR.15):11-23.

[4] Gong C , Xu D , Zhou Z, et al. BPNN-Based RealTime Recognition of Locomotion Modes for an Active Pelvis Orthosis with Different Assistive Strategies*[J]. International journal of humanoid robotics, 2020, 17(1):2050004.1-2050004.18.

[5] Li X , Ghosh J K, Fine P M , et al. Responsive highresolution air quality index mapping using model, regulatory monitor, and sensor data in real-time[J]. Environmental Research Letters, 2020, 15(10):1040.

[6] Ray P P , Thapa N , Dash D , et al. Novel implementation of IoT based non-invasive sensor system for real-time monitoring of intravenous fluid level for assistive e-healthcare $[\mathrm{J}]$. Circuit World, 2019, 45(3):109-123. 
[7] Ginigeme K , Wang Z . Distributed Optimal Vehicle-To-Grid Approaches With Consideration of Battery Degradation Cost Under Real-Time Pricing[J]. IEEE Access, 2020, 8(7):5225-5235.

[8] Chang B , Zhang L , Li L , et al. Optimizing Resource Allocation in URLLC for Real-Time Wireless Control Systems[J]. IEEE Transactions on Vehicular Technology, 2019, 68(9):8916-8927.

[9] Milton M , Castulo A D L O , Ginn H L , et al. Controller-Embeddable Probabilistic Real-Time Digital Twins for Power Electronic Converter Diagnostics[J]. IEEE Transactions on Power Electronics, 2020, PP(99):1-1.

[10] Younghoon K, Jeffrey H . Assessing Effects of Task and Data Distribution on the Effectiveness of Visual Encodings[J]. Computer Graphics Forum, 2018, 37(3):157-167.

[11] Geng S , Wang W , Yang X , et al. Research on high speed data distribution technology based on kernel state of domestic operating system[J]. MATEC Web of Conferences, 2020, 309(11):04019.

[12] Agarwal T , Niknejad P , Barzegaran M R , et al. Multi-level Time-Sensitive Networking (TSN) using the Data Distribution Services (DDS) for Synchronized Three-Phase Measurement Data Transfer[J]. IEEE Access, 2019, PP(99):1-1. 